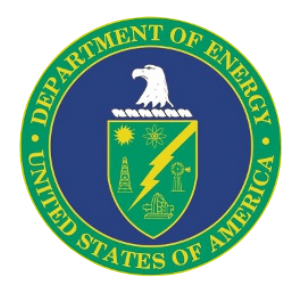

\title{
'Race' and the human genome
}

This supplement has its origins on May 15, 2003, when the National Human Genome Center at Howard University held a small but important workshop in Washington DC. The workshop, Human Genome Variation and 'Race', and this special issue of Nature Genetics were proposed by scientists at Howard University and financially supported by the Genome Programs of the US Department of Energy, through its Office of Science; the Irving Harris Foundation; the National Institutes of Health, through the National Human Genome Research Institute; and Howard University. As summarized by Francis Collins, director of the National Human Genome Research Institute, the workshop focused on several key questions: "What does the current body of scientific information say about the connections among race, ethnicity, genetics and health? What remains unknown? What additional research is needed? How can this information be applied to benefit human health? How might this information be applied in nonmedical settings? How can we adopt policies that will achieve beneficial societal outcomes?" This supplement, supported by the Department of Energy through a grant to Howard University, contains articles based on the presentations at this workshop.

With very rare exceptions, all of us in the US are immigrants. We bring with us a subset of genes from our homelands, and for many Americans, often first-generation but more commonly second-generation, the plural noun 'homelands' is appropriate. From this perspective, the most immediately obvious characteristic of 'race' is that describing most of us as Caucasian, Asian or African is far too simple. Despite attempts by the US Census Bureau to expand its definitions, the term 'race' does not describe most of us with the subtlety and complexity required to capture and appreciate our genetic diversity. Unfortunately, this oversimplification has had many tragic effects. Therefore, we need to start with the science, which is what the Howard University conference did. To quote further from Francis Collins' excellent commentary, "As a historically black university, Howard University served science and society by sponsoring this frank discussion, and the National Human Genome Center's leaders are to be congratulated for their vision in putting together such a thought-provoking agenda.... I completely agree.
If 'race' as a concept is oversimplified, what can or should we use to describe and define our heritage or familial lineage? Ethnicity, genetics, ancestry, lineage and family all denote something about our origins, but what? Perhaps the more immediate question is whether the completed Human Genome Project will define a concept of race that is scientifically credible and useful. Can a more thorough look at the genetic complement, the actual DNA sequences we each carry, clarify and inform our history and relationships? At the simplest level, each of us carries a set of genes that affects the color of his or her skin (often a surrogate for race). The exact number of these genes isn't known (PLoS Biology 1, 19-22; 2003), but they represent only a small fraction of the estimated 30,000 total genes in our genomes (Nature 409, 860-921; 2001; and Science 291, 1304-1351; 2001). We are genetically far more nuanced and variable than is reflected in just skin coloration. With more data, can we build a comprehensive understanding of ourselves, backed by societal strictures that encourage the beneficent use of the resulting knowledge rather than an urge to discriminate? Can we follow Aristotle's advice to "...venture on the study of every kind of animal without distaste; for each and all will reveal to us something natural and something beautiful. Absence of haphazard, and conduciveness of everything to an end, are to be found in Nature's works in the highest degree, and the resultant end of her generation and combinations is a form of the beautiful." (On the Parts of Animals, Oxford, 1911)?

Why is it important to achieve a closer approximation of the genetic reality in individual humans? From a medical perspective, knowing the unique genetic profile of an individual, a profile that is unquestionably influenced by ancestry, will assist a physician in streamlining the search for the right diagnosis for a set of symptoms. In the end, each person must be treated as an individual with his or her own medical issues, rather than as an exemplar of a race. We anticipate a future in which accurate predictive medicine, based on one's individual genetic profile, will promote longer and healthier lives and a better ability to manage interactions with our environment and the challenges it constantly presents, be they allergens, diseases or environmental hazards. If nothing else, among so many potential benefits, the kind of solid science presented and discussed in this 
issue and at the Howard conference is providing proof that oversimplified concepts of race simply don't work in any objective realm. It's bad medicine, and it's bad science.

The DOE has a health effects mission (rooted in the original enabling legislation for the precursor Atomic Energy Commission) to explore radiation effects on human health. Radiation-caused mutagenesis was the original impetus for DOE's involvement in genetics, and the effort to map and sequence the human genome was conceived at the DOE to develop the technologies and to build a reference sequence for subsequent biological science. Today, the DOE is a mission agency whose task is to pursue science to address national needs in clean energy production, legacy waste cleanup and global climate management. My office is currently addressing this imperative through its Genomics:GTL program, which seeks an understanding of microbial systems whose capabilities can ultimately be harnessed for biotechnology applications (http://DOEGenomestolife.org). Like the US National Institutes of Health's Genome Program, the DOE Human Genome Program responded to the need for recognition and study of the potential ethical, legal and social impacts of the science we supported and crafted our program to explore genome-derived societal issues. Although the list of ethical, legal and social issues is long, perhaps none is as important as understanding how our genetic endowments influence our many complex characteristics and defining the limits of these genetic contributions. We are much more than just the sum of our genes.

To bring light (rather than more heat) to this discussion, we are proud to have supported the Howard University workshop and this issue, which will enable a far larger audience to join in this most vital discussion. Entrusted with public funds to carry out the science, we can do no less. Although much remains to be done, the determination of the human genome sequence gives us solid ground from which to move forward.

Ari Patrinos Director for Biological and Environmental Research Office of Science US Department of Energy 